\title{
Measuring awareness about child abuse and neglect: Validity and reliability of a newly developed tool-child abuse and neglect awareness scale
}

\author{
Hüsniye Altan ${ }^{1}$, Işıl İrem Budakoğlu², Figen Şahin-Dağl1 ${ }^{3}$, Resmiye Oral ${ }^{4}$ \\ ${ }^{1}$ Department of Pediatrics, Ankara Children's Hematology and Oncology Training and Research Hospital, Departments \\ ${ }^{2}$ Medical Education and ${ }^{3}$ Social Pediatrics, Gazi University Faculty of Medicine, Ankara, Turkey; ${ }^{4}$ Department of Pediatrics, \\ University of Iowa Children's Hospital, Iowa City, United States. E-mail: husniyealtan@yahoo.com \\ Received: 6th September 2017, Accepted: 30th October 2017
}

\begin{abstract}
SUMMARY: Altan H, Budakoğlu Iİ, Şahin-Dağlı F, Oral R. Measuring awareness about child abuse and neglect: Validity and reliability of a newly developed tool-child abuse and neglect awareness scale. Turk J Pediatr 2018; 60: 392-399.

In this study, we aimed at determining child abuse and neglect awareness of medical students attending one of the top medical schools in Turkey. The study group comprised 350 third-year medical students at Gazi University, School of Medicine, Ankara. The items in the scale were prepared by two experienced pediatricians and revised according to feedback received from two pilot studies and experts in this field of study. A 20-item "Child Abuse and Neglect Awareness" scale (CANA-S) was developed by an expert panel. Exploratory and confirmatory factor analyses were performed. We also measured test-retest reliability and internal consistency. Conformity for factor analysis of the scale's construct validity revealed a Kaiser-Meyer-Olkin sample concordance coefficient of 0.799 . For the Bartlett Sphericity test, $\chi 2$ value was $1157.750(\mathrm{p}<0.01)$. Based on these analyses, the scale explains $44.9 \%$ of the total variance and consists of 20 items and 4 subscales. Cronbach's alpha value and correlation coefficient were 0.768 and $r=0.204 \quad(p=0.045)$, respectively. This scale is a valid and reliable measurement tool for evaluating awareness about child abuse and neglect among the medical students.
\end{abstract}

Key words: child abuse and neglect, scale, survey, awareness, education programs.

Child maltreatment is abuse or neglect of a child by a parent or other caregiver, which results in potential or actual harm or threats of harm to the child. ${ }^{1}$ Maltreatment encompasses both acts of commission (abuse) and omission (neglect). Child maltreatment is divided into four categories: 1) physical abuse (e.g., kicking, hitting, punching, or beating); 2) sexual abuse (e.g., rape or fondling); 3) psychological abuse (e.g., isolating, blaming, or belittling); and 4) neglect or failing to meet a child's basic physical, emotional, or educational needs (e.g., not providing nutrition, clothing, hygiene, medical or mental health care) or failure to supervise the child in a way that ensures the child's safety (e.g., not taking reasonable steps to prevent injury). ${ }^{1,2}$
Many cases of child abuse are never reported to the authorities; therefore, the actual prevalence of child maltreatment is likely much greater than that is officially recorded. ${ }^{3}$ In Turkey, in a study conducted on 7,540 children aged 11 , 13 , and 16, respondents reported high levels of adverse childhood experiences (both over a lifetime and within the past year), including psychological (70.5\% and $62.7 \%$, respectively), physical (58.3\% and $46.0 \%$, respectively), and neglect $\left(42.6 \%\right.$ and $37.5 \%$, respectively). ${ }^{4}$ Similar to the NIS-4 study conducted in the USA, the number of cases reported to authorities is very low compared to the number reported by children themselves (personal communication on an unpublished study).

Prevention of child maltreatment requires multi- 
faceted intervention modalities that embrace all levels (individual, family, community, and societal) of the ecological system. Prevention strategies include effective programs that focus on changing attitudes and modifying policies and societal norms to create safe, stable, and nurturing environments. Implementing prevention programs at primary, secondary, and tertiary levels and improving professional and societal understanding and awareness of child maltreatment are important essential primary steps.

We used this understanding to develop parenting education programs to educate parents of large and at-risk families. ${ }^{5,6}$ In addition, experts have developed curricula to train pre-professionals and professionals on the fundamentals of child maltreatment. ${ }^{7-9}$ Finally, governments have developed mandatory inservice training models for professionals. ${ }^{10,11}$

To compare data among different societies and cultures in the field of child maltreatment, multiple tools were specifically developed to measure the incidence or recognize the symptoms of child abuse, such as Childhood Trauma Questionnaire (CTQ) ${ }^{12}$, Recognition of Emotional Maltreatment Scale (REMS) ${ }^{13}$, Child Abuse Blame Scale-Physical Abuse Japanese version (CABS-PA-J) ${ }^{14}$, and Child Abuse and Neglect Signs Scale (CANSS). ${ }^{15}$

When developing meaningful educational curricula, it is important to recognize the target population's baseline level of awareness and understanding. Thus, the aim of this study was to measure third-year medical students' awareness about child abuse and neglect using a new valid and reliable scale, developed by a focus group.

\section{Material and Methods}

\section{Design and Participants}

The study group consisted of 350 third-year medical students of Gazi University, School of Medicine, with no prior training/education on child abuse and neglect. One hundred and thirty $(37.14 \%)$ out of 350 third-year students participated in the first test, and 272 students $(77.71 \%)$ participated in the second test (retest).

An informed consent form was obtained from the students who participated in the study. The Gazi University Ethical Commission approved the study (Date 02.07.2014; No: 77082166604.01.02-18605).

\section{Literature review and development of the pool of items}

We screened databases such as Pubmed, Cochrane, EBSCO, the Turkish citation index, and TUBITAK Turkish medical index. Some psychometrically robust instruments in the field of child abuse and neglect were found; CTQ measures the knowledge of frequency and severity of types of abuse and neglect ${ }^{12}$, REMS measures recognition of emotional maltreatment ${ }^{13}$, CABS-PA-J measures Japanese mothers' recognition of child abuse ${ }^{14}$, and CANSS measures teachers' recognition of signs that might indicate child maltreatment. ${ }^{15}$ Some scales use short vignettes to measure understanding of a given abuse scenario. ${ }^{16}$

After a comprehensive literature review with special focus on Centers for Disease Control and Prevention (CDC) study, the first draft of "Child Abuse and Neglect Awareness Scale" (CANA-S) with 25 short vignettes was developed by two pediatricians (HA, FSD) who were clinically experienced in the field of child abuse and neglect. Each vignette described one of the four major forms of abuse: physical, sexual, emotional and neglect. ${ }^{1}$

\section{Validity Analyses}

The pilot study revealed no overt issues regarding the design of the scale.

\section{Content Validity}

To test content validity, we convened an expert review panel comprising 12 health professionals.

Table I. Subscales of Child Abuse and Neglect Awareness Scale (CANA-S).

\begin{tabular}{ll}
\hline Subscales of CANA-S & Scale Items \\
\hline Physical abuse & $4,9,13,15,18$ \\
Sexual abuse & $6,7,11,17,20$ \\
Emotional abuse & $8,10,14,16,19$ \\
Neglect & $1,2,3,5,12$ \\
\hline
\end{tabular}


Table II. Factor Analysis of the Items in the Child Abuse and Neglect Awareness Scale (CANA-S).

1. Serap and her taxi driver husband report that they take their children, 1 and 4 years old, to a family healthcare centre only for their vaccinations and they think that there is no need to take them to hospital unless their children are ill.

2. The mother of Rana (7 years old), kisses Rana's brothers, 4 and 5 years of age good night when she puts them to sleep but she does not kiss Rana. Her defense for that is Rana is too old for this.

3. When Ali, 3 years old, and his brother go to the family healthcare center when his brother is ill, the doctor realizes that Ali is not wearing socks and is wearing only a thin sweater despite the cold weather. The doctor warns his mother angrily and Ali's mother tells the doctor that she cannot afford them because of poverty.

4. The Department of Social Services takes a protective order for 3 children who are frequently beaten by their alcoholic father and whose mother says that they are so mischievous that sometimes they deserve to be beaten.

5. Fatma leaves her two children, 4 and 6 years old, alone at home by locking them in, when she goes shopping for 2-3 hours.

6. The father of Cem (13 years old) realizes that Cem visits pornographic websites. He talks to Cem face to face and says that it is normal for him to wonder about these things but the things he sees on these websites are not appropriate for him and tells him Cem can ask him about anything that he is curious about.

7. Emel, who is 7 years old tells her mother, "When you are at your night shift, daddy and I sleep together. Because it is too hot, my father takes off our clothes". The mother confirms and says, "Right, it is too hot."

8. Ahmet comes from work and sees that his two sons, 11 and 13 years old, are having a fight and Ahmet tells them to learn to solve their problems and that he will not interfere.

9. The doctor who examines Kaya, who is 8 years old and is taken to the hospital with complaints of cough, sees bruises on his back and torso which have a pattern of new and old belt marks. The child says he has fallen down but the doctor does not find him convincing and files a report with the police.

10. Although her mother tells her not to jump on her bed so that she wouldn't fall off, Seda, who is 2 years old, continues to jump on the bed. She falls off her bed when she loses her balance. Her mother says "It serves you right! If you do not listen to your mother words, that's what will happen to you!"

11. Elif, who is 16 years old, tells her mother that she likes their neighbour's son Orhan 17 years old, very much and that Orhan kissed her on the lips. Her mother warns her about not going further.

12. Emre, who is 12 years old, is often late for school and sometimes he does not go school. His teacher overlooks this situation because of the fact that his parents are divorced.

13. A father who beats up his five children occasionally says, "What else can I do? All of them are so naughty. They do not listen to me. I come home tired and I also have to deal with their fights. I sometimes slap them in the face slightly, just to discipline them. My father used to beat me for my own sake, too."

14. Semiha, who is 13 years old, dusts and tidies up her room since her mother has asked her to help her with the household chores.

15. Hacer sees her neighbor Ayşe while Ayşe is beating her sons, 3 and 6 years old, when they misbehave. Hacer reports it to the police station in the neighborhood.

16. Ayşe, who is 15 years old, tells her mother that she wants to dye her hair blonde. Her mother threatens her by saying "If you do so, I will not let you come home."

17. Serap, who is 14 years old, falls in love with her cousin 20 years old. Her mother sees them while they are kissing. Her mother tells Serap "We should not tell anyone about it. No one should hear it; otherwise, we will be disgraced."

18. Murat, who is 5 years old, says "You are stupid!" to his mother when he gets angry with her. Her mother throws the slipper in her hand towards Murat's head.

19. Ayşe permits her daughter Nehir, 17 years old, to come home before Midnight when she goes out with her friends but she tells her daughter Pinar, who is 12 years old, to come home at 20.00 at the latest.

20. While Elif who is 4 years old, is playing with her cousin Nusret, 5 years old, Elif's mother sees that Nusret pulls up Elif's skirt and looks under it. Elif's mother does not get angry with them since they are children and tells them that it is not right to look at others' private body parts. 
The panel, all of whom were board members of the Turkish Society for Prevention of Child Abuse and Neglect (TSPCAN), reviewed case vignettes. These experts were from different disciplines such as child psychiatry, pediatrics, psychology, social work, forensic medicine, and they were actively involved in the management of abused and neglected children in their professional lives.

Once the draft was edited and approved by the expert panel, we conducted a pilot study with 21 sixth-year medical students at Gazi University School of Medicine. In the pilot study, students were asked to evaluate the expressions in the vignettes in terms of meaningfulness, readability, clarity of meaning, and sentence length. After students' feedback, the wordings of several items were changed and the study tool was finalized.

The CANA-S comprised 4 sections of vignettes, each section comprising a subscale dedicated to one of the major categories of child abuse and neglect: physical abuse, sexual abuse, emotional abuse, and neglect (Table I). Responses are provided on a five-point Likert scale over 20 items: 11 negative $(1,2,3,5,7,10,12,13,16$, $17,18)$ and nine positive. The positive items in the scale were scored from 5 to 1 as follows: "definitely appropriate $=5$," "appropriate $=$ 4," "uncertain $=3$," "inappropriate $=2$," and "definitely inappropriate $=1$." The negative items were scored from 1 to 5 as follows: "definitely appropriate $=1$," "appropriate $=2$," "uncertain $=3$," "inappropriate $=4$," and "definitely inappropriate $=5$ " (Supplementary data).

The highest and lowest possible scores for the full scale are 100 (indicating the highest level of awareness) and 20 (indicating the lowest level of awareness), respectively whereas Those for the subscales are 25 and 5, respectively.

\section{Construct Validity}

We analyzed the construct validity of the scale using Exploratory Factor Analysis (EFA). The applicability of the factor analysis was determined according to the results of the Kaiser-Meyer-Olkin (KMO) and Bartlett test of Sphericity. Principal component analysis and varimax rotation using EFA determined the number of the subscales.

After the factor analysis, the items with factor loadings above 0.3 were used to estimate a total score for each subscale. The cut-off point for the factor loading value was $0.30 .{ }^{17}$ Only one item had a factor loading $<0.30$, but because it was very close $(0.291)$ to the cut-off point, the expert panel decided to retain it.

\section{Reliability Analysis}

Reliability was assessed through test-retest methods (Test-rt) and internal consistency; these were done 15 days after the first administration. Participants were informed that their participation was voluntary and all questionnaires were individually completed in classrooms at the Gazi University School of Medicine. The researchers were present to answer any questions from the participants while they filled out the questionnaires.

\section{Statistical Analysis}

For the statistical analyses, we used the Statistical Package for Social Sciences (SPSS) 15.0. Confirmatory factor analysis evaluated the construct validity of the scale. For internal consistency and reliability, Cronbach's alpha and Pearson correlation coefficients were calculated. Cronbach's alpha value $>0.7$ was indicative of internal consistency. ${ }^{18}$

\section{Results}

The study group comprised 146 (53.70\%) females and $126(46.30 \%)$ male students (age range: 18-26 years, median age: 21 years).

Validation and reliability testing of the scale revealed the following: Factor analysis of the scale's construct validity revealed conformity of 0.799 , and conformity for Bartlett Sphericity $\chi 2$ test value was $1157.750(\mathrm{p}<0.01)$. We developed a 20 -item scale (and four subscales) with a total variance of $44.9 \%$ (Table II). For the neglect subscales, factor loading varied between 0.461 and 0.641; for physical abuse it was between 0.434 and 0.750 ; for sexual abuse it varied between 0.403 and 0.639; and for emotional abuse it was between 0.291 and 0.683 . Cronbach's alpha value was 0.768 (Table III) via internal consistency reliability analysis. The correlation coefficient was $r=0.204$, $p$ $=0.045$ in Test-rt.

The mean scores of university students' responses to statements of child abuse and neglect awareness are shown in Table IV. 
Table III. Cronbach's Alpha Values for Child Abuse and Neglect Awareness Scale (CANA-S).

\begin{tabular}{lcc}
\hline Subscales of CANA-S & Number of Items & Cronbach's alpha \\
\hline Factor 1-Physical abuse & 5 & 0.545 \\
Factor 2-Sexual abuse & 5 & 0.208 \\
Factor 3-Emotional abuse & 5 & 0.297 \\
Factor 4-Neglect & 5 & 0.680 \\
\hline Total & 20 & 0.768 \\
\hline
\end{tabular}

\section{Discussion}

CANA-S is a valid and reliable scale for measuring child abuse and neglect awareness in third-year medical students.

Child abuse and neglect is an important problem that can have immediate and long term consequences for victims. Increased societal awareness could prevent child abuse and neglect. We selected university students and parents because increasing these groups' awareness may result in increased responsible and corrective behaviors. ${ }^{19}$ These may result in early diagnosis of child abuse and neglect, thereby decreasing its recurrence.

Cognitive awareness combines learning how to learn, focusing attention, step by step work-planning, learning stage evaluation, and executing necessary corrections and adjustments. ${ }^{19}$ In this framework, cognition includes mental processes such as perception, comprehension, and remembrance. Metacognition refers to an individual's recognition of mental processes such as his/ her own perception, comprehension, and remembrance. ${ }^{20}$ Prevention of a problem is closely associated with the cognitive awareness of the involved individuals. ${ }^{19}$ The first step to preventing child abuse is to define what constitutes abuse and neglect in a culturally competent manner, and using this, enhance awareness of child abuse and neglect within the society.

We need to implement effective prevention strategies to stop child abuse and neglect before it happens, while fostering commitment to social change. ${ }^{21}$

Reliability and validity measures are essential for scale development. Reliability refers to the consistency of the measure across time, raters, and occasions. To check whether a scale is reliable or not, its internal consistency (IC) and test-rt reliability tests must be conducted. ${ }^{22,23}$ IC is based on single administration and represents "the average of the correlation among all the items in the measure," 23,24 which is calculated using Cronbach's alpha. ${ }^{25,26}$ Stability of measures over time and across raters is measured by Test-rt, defined as observation conducted on two occasions, separated by a time interval.

Validity refers to whether a measure assesses the condition, event, or phenomena that it was developed to assess. ${ }^{23,25}$ As our study was the first attempt to develop a child abuse-related scale, it was hard to provide the content validity. Nevertheless, it has been thought that the content validity of the scale is sufficiently provided by consulting experts who are highly experienced in their fields.

For this study, we completed a factor analysis for construct validity. Items with factor loading $>0.3$ were accepted as scale item. Only one item with a factor loading of under 0.3 (0.291) was added to the scale under the emotional abuse subgroup. Emotional abuse is difficult to define and prove, making it harder to understand than other types of abuse. ${ }^{27}$ Thus, factor loading for emotional abuse may be seen in lower levels.

Some examples found during screening procedures were as follows: CABS-PA-J was effective for determining child abuse recognition among Japanese mothers. ${ }^{14}$ The CANSS was developed to measure teachers' recognition of signs that might indicate child maltreatment. ${ }^{15}$ Giovannoni and Becerra ${ }^{16}$ describe various forms of child abuse and neglect in short vignettes.Modifications of these vignettes were used in several studies where respondents were instructed to rate the seriousness of the abuse. The responses to each vignette were separately analyzed. ${ }^{28,29}$

Other example studies include CTQ a 
retrospective measure of the frequency and severity of different types of abuse and neglect. ${ }^{12}$ The original questionnaire consisted of 70 items, which asked clients to rate frequencies $(0=$ never true, $5=$ very often true $)$. A sample item for physical neglect was as follows: "There was enough food in the house for everyone." The following was the item that was related to the occurrence of emotional neglect: "People in my family did not seem to know or care what I was doing." Physical and emotional abuse were detected with questions such as "I was punished with a belt, board, cord, or some other hard object," or "People in my family said hurtful and insulting things to me." The item about sexual abuse was "Someone tried to touch me in a sexual way or to make me touch them." 12

Another study, conducted in Turkey, evaluated the perceptions and attitudes toward child neglect, in a group of mothers. The behavioral questionnaire descriptions and scenarios were selected from a pool of questions about perceived neglect, attitudes, and case examples used in similar studies. ${ }^{30}$ This study concluded that to construct effective preventive strategies, traditional community perspectives and cultural characteristics regarding child neglect should be articulated. ${ }^{30}$

REMS assesses the recognition of emotionally abusive parenting practices and interactions with other children. In this study, ${ }^{21}$ short vignettes were used. Topics included inappropriate play activities, punishing children for minor misbehaviors, comparing children with their peers, and refusing to speak to the child. ${ }^{13}$ Our study used 20 vignettes, different from REMS, which used all the vignettes related to

Table IV. Mean Scores of University Students on the Child Abuse and Neglect Awareness Scale.

\begin{tabular}{|c|c|c|c|c|}
\hline \multirow[t]{2}{*}{ Item } & \multicolumn{2}{|c|}{ Test } & \multicolumn{2}{|c|}{ Re-test } \\
\hline & Mean $\pm S D$ & Median (Min-Max) & Mean $\pm S D$ & Median (Min-Max) \\
\hline 1 & $3.75 \pm 0.92$ & $4.0(2-5)$ & $3.72 \pm 0.92$ & $4.0(2-5)$ \\
\hline 2 & $4.70 \pm 0.54$ & $5.0(2-5)$ & $4.37 \pm 0.76$ & $5.0(1-5)$ \\
\hline 3 & $3.61 \pm 0.79$ & $4.0(1-5)$ & $3.55 \pm 0.73$ & $3.0(2-5)$ \\
\hline 4 & $4.11 \pm 1.04$ & $4.0(1-5)$ & $3.56 \pm 1.19$ & $4.0(1-5)$ \\
\hline 5 & $4.55 \pm 0.72$ & $5.0(1-5)$ & $4.31 \pm 0.83$ & $4.0(1-5)$ \\
\hline 6 & $3.93 \pm 0.97$ & $4.0(1-5)$ & $3.64 \pm 0.98$ & $4.0(1-5)$ \\
\hline 7 & $3.82 \pm 0.90$ & $4.0(2-5)$ & $3.66 \pm 0.95$ & $4.0(1-5)$ \\
\hline 8 & $3.24 \pm 0.88$ & $3.0(1-5)$ & $3.16 \pm 0.93$ & $3.0(1-5)$ \\
\hline 9 & $4.46 \pm 0.69$ & $5.0(1-5)$ & $4.00 \pm 0.89$ & $4.0(1-5)$ \\
\hline 10 & $3.81 \pm 0.82$ & $4.0(1-5)$ & $3.80 \pm 0.79$ & $4.0(1-5)$ \\
\hline 11 & $3.31 \pm 0.91$ & $3.0(1-5)$ & $3.22 \pm 0.89$ & $3.0(1-5)$ \\
\hline 12 & $4.31 \pm 0.63$ & $4.0(2-5)$ & $3.81 \pm 0.90$ & $4.0(1-5)$ \\
\hline 13 & $3.86 \pm 0.90$ & $4.0(1-5)$ & $3.95 \pm 0.76$ & $4.0(2-5)$ \\
\hline 14 & $4.33 \pm 0.65$ & $4.0(2-5)$ & $3.91 \pm 0.92$ & $4.0(1-5)$ \\
\hline 15 & $3.90 \pm 0.91$ & $4.0(1-5)$ & $3.56 \pm 1.10$ & $4.0(1-5)$ \\
\hline 16 & $3.81 \pm 0.82$ & $4.0(1-5)$ & $3.84 \pm 0.81$ & $4.0(1-5)$ \\
\hline 17 & $3.76 \pm 0.88$ & $4.0(1-5)$ & $3.61 \pm 0.93$ & $4.0(1-5)$ \\
\hline 18 & $3.69 \pm 0.96$ & $4.0(1-5)$ & $3.70 \pm 0.93$ & $4.0(1-5)$ \\
\hline 19 & $3.42 \pm 0.86$ & $4.0(1-5)$ & $3.16+0.94$ & $3.0(1-4)$ \\
\hline 20 & $3.87 \pm 0.75$ & $4.0(1-5)$ & $3.52 \pm 0.94$ & $4.0(1-5)$ \\
\hline
\end{tabular}

SD: standard deviation. The positive items in the scale were scored from 5 to 1 as follows: "definitely appropriate $=5$," "appropriate =4," "uncertain=3," "inappropriate $=2$," and "definitely inappropriate $=1$." The negative items were scored from 1 to 5 as follows: "definitely appropriate=1," "appropriate=2," "uncertain=3," "inappropriate=4," and "definitely inappropriate $=5 "$ 
emotional abuse, and only five vignettes tested students' awareness of emotional abuse and thus, the scale's Cronbach's alpha of internal consistency was lower than the REMS.

Another scale is the CANSS, a 34-item, 5-point Likert-type scale with responses ranging from strongly agree to not agree (5 to 1 ), relating to the degree where each statement represents child maltreatment. Unlike the CANSS, where items were taken from previously used scales, in the present study, the study research team designed the instruments. Items created during scale preparation were indicators of child abuse and neglect, collected through literature review. ${ }^{15}$ However, our study items were original.

Students' highest mean scores were in the items concerning neglect such as "The mother of Rana, aged 7, kisses Rana's brothers, aged 4 and 5, says "Good night!" when she puts them to sleep, but she does not kiss Rana by saying she is too old for this." $(M=4.70)$. The mean neglect scores, indicating failure to show love and affection, may be high because they are easily identified. The lowest mean scores were related to emotional abuse items such as "Ahmet comes from work and sees that his two sons, aged 11 and 13, are having a fight, and Ahmet tells them to learn to solve their problems and that he will not interfere." $(M=3.24)$. The fact that it has the lowest mean score can be attributed to the lack of visible signs of emotional abuse.

Our goal was to develop such a scale. The CANA-S can be used to measure training effects for child abuse and neglect awareness education efforts. Although the scale was initially administered to medical students, we believe they are no different from other students owing to little exposure to this subject.

Nevertheless, this study has limitations. Because our scale was created for evaluating medical students' awareness about child abuse and neglect, its use is limited to medical students within this age range. In spite of this, the internal consistency was high (0.768). Test-rt results $(r=0.204)$ were statistically significant despite their weak correlation. The correlation coefficient might have been calculated weak due to the lesser number of participants in the study.
Through cooperation with expert scholars, we developed the CANA-S for measuring medical students' awareness of child abuse and neglect. Our future efforts will be directed toward making an internationally recognized measure.

The CANA-S is a tool for use when selecting and evaluating medical students who are attending training programs on child abuse and neglect.

The CANA-S is a valid and reliable scale for measuring child abuse and neglect awareness in third-year medical students in the Gazi University, School of Medicine. This is the first study of its kind and various experts, from different fields, contributed to its development. To improve the scale, increase scale feasibility, and extend its use, future studies should involve students from other faculties and departments. Future efforts should enhance the validity and reliability of our scale through studies that involve more participants and take into account the cultural context of the participants.

\section{Supplementary data is available at:}

http://www.turkishjournalpediatrics.org/ uploads/turkjped.2018.04.006.S1.pdf

\section{REFERENCES}

1. Child Maltreatment Surveillance: Uniform Definitions for Public Health and Recommended Data Elements, Version 1.0. Atlanta (GA): Centers for Disease Control and Prevention, National Center for Injury Prevention and Control, 2008. Available at: https://www.cdc.gov/ violenceprevention/pdf/cm_surveillance-a.pdf Accessed on: 14th November 2015.

2. Sexual Violence Surveillance: Uniform Definitions and Recommended Data Elements, Version 2.0. Atlanta (GA): National Center for Injury Prevention and Control, Centers for Disease Control and Prevention, Atlanta, Georgia, 2014. Available at: https://www.cdc.gov/ violenceprevention/pdf/sv_surveillance_definitionsl2009-a.pdf Accessed on: 14th November2015.

3. Fourth National Incidence Study of Child Abuse and Neglect (NIS-4): Report to Congress. Washington, DC: US Department of Health and Human Services Administration for Children and Families, 2010. Available at: http://www.acf.hhs.gov/sites/default/files/ opre/nis4_report_congress_full_pdf_jan 2010 Accessed on: 2nd January 2016.

4. Sofuoğlu Z, Oral R, Aydın F, et al. Epidemiological study of negative childhood experiences in three provinces of Turkey. Turk Pediatri Ars 2014; 49: 47-56.

5. Huber A, McMahon CA, Sweller N. Efficacy of the 20-week circle of security intervention: Changes in caregiver reflective functioning, representations, and child attachment in an Australian clinical sample. Infant Ment Health J 2015; 36: 556-574. 
6. Pickering JA, Sanders MR. Reducing child maltreatment by making parenting programs available to all parents: A case example using the triple P-positive parenting program. Trauma Violence Abuse 2016; 17: 398-407.

7. Damashek A, Balachova T, Bonner B. Training competent psychologists in the field of child maltreatment. J Clin Psychol 2011; 67: 752-757.

8. Heck NC, Saunders BE, Smith DW. Web-based training for an evidence-supported treatment: Training completion and knowledge acquisition in a global sample of learners. Child Maltreat 2015; 20: 183-192.

9. Raja S, Rajagopalan CF, Kruthoff M, Kuperschmidt A, Chang P, Hoersch M. Teaching dental students to interact with survivors of traumatic events: Development of a two-day module. J Dent Educ 2015; 79: 47-55.

10. University of Iowa Department of Public Health. Training for Identifying and Reporting Abuse. Available at: http://idph.iowa.gov/abuse-ed-review. Accessed on: 1 st January 2017.

11. University of Pittsburgh School of Social Work. Child Welfare Education and Research Programs. Available at: www.reportabusepa.pitt.edu. Accessed on: 3rd January 2017.

12. Bernstein DP, Ahluvalia T, Pogge D, Handelsman L. Validity of the childhood trauma questionnaire in an adolescent psychiatric population. J Am Acad Child Adolesc Psychiatry 1997; 36: 340-348.

13. Uslu RI, Kapci EG, Yildirim R, Oney E. Sociodemographic characteristics of Turkish parents in relation to their recognition of emotional maltreatment. Child Abuse Negl 2010; 34: 345-353.

14. Fujimoto M, Hirose T, Nakayama T, Okawa H, Takigawa I. Measuring Japanese mothers' perception of child abuse: Development of a Japanese version of the child abuse blame scale -physical abuse (CABS-PA- J). Biopsychosoc Med 2007; 1: 14.

15. Karadag SC, Sonmez S, Dereobali N. An investigation of preschool teachers' recognition of possible child abuse and neglect. J Interpers Violence 2015; 30: 873-891.

16. Giovannoni J, Becerra R. Defining child abuse. New York: The Free Press, 1979.
17. Neale JM and Liebert RM. Science and behavior: An introduction to methods of research (3rd ed.). Englewood Cliffs, NJ: Prentice-Hall, 1986.

18. Nunnaly JC. Psychometric theory (2nd ed). New York: McGraw-Hill, 1978.

19. Paris SG, Winograd PW. How metacognition can promote academic learning and instruction. In: Jones BJ and Idol L (ed). Dimensions of thinking and cognitive instruction. Hillsdale, NJ: Lawrence Erlbaum Associates, 1990: 15-51.

20. Garner R, Alexander PA. Metacognition: Answered and unanswered questions. Educational Psychologist 1989; 24: 143-158.

21. Centers for Disease Control and Prevention (CDC), National Center for Injury Prevention and Control, Division of Violence Prevention, 2015. Available at: http://www.cdc.gov/violenceprevention/ childmaltreatment/prevention.html. Accessed on: 15th June 2015)

22. Sencan H. Sosyal ve Davranışsal Ölcümlerde Güvenilirlik ve Geçerlilik. In: Sencan H (ed.) Guvenilirlik (1st ed). Ankara: Seckin, 2005:11-36.

23. Streiner DL and Norman GR. Health measurement scales. A practical guide to their development and use. New York: Oxford University Press, 2008.

24. Cortina JM. What is coefficient alpha? An examination of theory and applications. J Appl Psychol 1993; 78: 98-104.

25. Keszei AP, Novak M, Streiner DL. Introduction to health measurement scales. J Psychosom Res 2010; 68: 319-323.

26. Cronbach LJ. Coefficient alpha and the internal structure of tests. Psychometrika 1951; 16: 297-334.

27. Tonmyr L, Draca J, Crain J, MacMillan HL. Measurement of emotional/psychological child maltreatment: A review. Child Abuse Negl 2011; 35: 767-782.

28. Pierce L, Bozalek V. Child abuse in South Africa: An examination of how child abuse and neglect are defined. Child Abuse Neglect 2004; 28: 817-832.

29. Segal U. Child abuse in India: An empirical report on perceptions. Child Abuse Negl 1992; 16: 887-908.

30. Polat S, Tasar A, Ozkan S. Perceptions and attitudes of mothers about child neglect in Turkey. Infants Young Children 2010; 23: 122-131. 